Для цитирования: Бебенин А.А. Роль органической дисфункции головного мозга в формировании неорганического энкопреза в детском возрасте. Сибирский вестник психиатрии и наркологии. 2020 ; 4 (109): 34-41. https://doi.org/10.26617/1810-3111-2020-4(109)-34-41

\title{
Роль органической дисфункции головного мозга в формировании неорганического энкопреза в детском возрасте
}

\section{Бебенин А.A.}

${ }^{1}$ ГБУЗ Свердловской области «Свердловская областная клиническая психиатрическая больница» Россия, 620030, Екатеринбург, Сибирский тракт, 8 км

\section{PEЗЮME}

В статье представлены результаты долгосрочного изучения неорганического энкопреза в детскоподростковом возрасте. Цель: изучение факторной обусловленности неорганического энкопреза, основанной на систематизации и анализе данных комплексного клинико-параклинического исследования (анамнестического, неврологического, электрофизиологического, нейропсихологического исследований). Материал и методы. В исследовании рассматривались 192 случая неорганического энкопреза с затяжным неблагоприятным течением. В исследовательскую выборку включены дети, страдающие энкопрезом неорганической природы (F98.1 по МКБ-10), в возрасте от 5 до 13 лет, с общим интеллектуальным показателем по шкале Векслера не ниже среднего уровня (90-109 баллов). Все дети обследованы педиатром и гастроэнтерологом для исключения патологии желудочно-кишечного тракта. Сравнение проведено с аналогичными показателями одновозрастных групп детей и подростков $(\mathrm{n}=100)$ - контрольная группа. В качестве основного метода применялся клинический с целью установления клинико-психопатологических, клинико-динамических закономерностей развития неорганического энкопреза. По результатам компьютерной ЭЭГ были верифицированы нарушения биоэлектрической активности головного мозга. Результаты. Комплексное клинико-параклиническое исследование продемонстрировало, что формирование энкопреза обусловлено резидуально-органической церебральной недостаточностью вследствие влияния патогенных факторов на раннем этапе онтогенеза (пренатальный и перинатальный периоды), выявленной в 100\% случаев. Достоверность органической дисфункции головного мозга при энкопрезе верифицирована данными неврологического, электрофизиологического, нейропсихологического исследований. Соотнесение отчетливых эпилептиформных паттернов ЭЭГ с клиническими проявлениями психоорганических нарушений свидетельствует о том, что в развитии энкопреза с затяжным неблагоприятным течением участвуют механизмы, схожие с эпилептогенезом.

Ключевые слова: энкопрез неорганической природы, патогенез, электроэнцефалограмма, нейропсихология, дети дошкольного и школьного возрастов.

\section{ВВЕДЕНИЕ}

В МКБ-10 неорганический энкопрез рассматривается в рубрике F98 как «Другие поведенческие и эмоциональные расстройства, начинающиеся обычно в детском и подростковом возрасте», несмотря на это, данной проблемой занимаются преимущественно гастроэнтерологи, неврологи, проктологи. Противоречия в основных подходах к пониманию и терапии расстройства приводят на практике к применению малоэффективных, порой взаимоисключающих технологий, преимущественно симптоматического характера $[1,2,3,4$, $5,6,8,9,16,17,18]$. Зачастую энкопрезу придается значение синдрома, исключая церебральные механизмы нарушенной регуляции выделительной функции. Длительное сосуществование пациента с болезнью, тем более при отсутствии патогенетически обоснованной терапии, приводит к присоединению вторичных по отношению к энкопрезу невротических расстройств, отражающих реакцию личности на болезнь и её интерпретацию, что позволяет исследователям рассматривать психогенную природу расстройства $[1,2,3$, $6,7,8,9,16,17,18]$.

В связи со сказанным энкопрез приобретает затяжное течение с частыми рецидивами, что предопределяет снижение социального функционирования и обусловливает стойкую дезадаптацию детей.

Только установление центральных патогенетических механизмов энкопреза, позволяющих в недалекой перспективе разработать эффективные стратегии терапии, поможет решить обозначенную проблему. В контексте изложенного весьма актуальным представляется более глубокое изучение патогенеза энкопреза, опираясь на современный биопсихосоциальный подход к диагностике, терапии и реабилитации заболеваний, включающий полипрофессиональное и межведомственное участие. 


\section{ЦЕЛЬ ИССЛЕДОВАНИЯ}

Изучение факторной обусловленности неорганического энкопреза, основанной на систематизации и анализе данных комплексного клиникопараклинического исследования (анамнестического, неврологического, электрофизиологического (КЭЭГ), нейропсихологического исследований).

\section{МАТЕРИАЛЫ И МЕТОДЫ}

В исследование включены дети, страдающие энкопрезом неорганической природы (F98.1 по МКБ-10), в возрасте от 5 до 13 лет, имеющие общий интеллектуальный показатель (ОИП) по шкале Векслера не ниже среднего уровня (от 90 до 109 баллов). К основной группе отнесены 192 случая неорганического энкопреза с затяжным неблагоприятным течением. Все дети в обязательном прядке были обследованы педиатром и гастроэнтерологом для исключения патологии желудочно-кишечного тракта. Сравнительный анализ проводился с аналогичными показателями одновозрастной группы детей и подростков в количестве 100 человек, посещавших общеобразовательные средние школы (контрольная группа).

Клинический метод, как основной, применялся с целью установления клинико-психопатологических, клинико-динамических закономерностей развития неорганического энкопреза.

Результаты компьютерной ЭЭГ, полученные в ходе исследования, позволили верифицировать нарушения биоэлектрической активности головного мозга. ЭЭГ проводилась с частотой не реже 1 раза в 6 месяцев. Нейропсихологическое исследование подростков проводилось по методике адаптированного нейропсихологического исследования, разработанной Всероссийским центром по детской неврологии и предназначенной для детей преимущественно дошкольного и младшего школьного возрастов.

Для статистического анализа данных и графической презентации полученных статистических данных были использованы пакеты прикладных программ Microsoft Office 2016 и SPSS, версия 17.0 for Windows v.10. Качественные признаки описывали простым указанием количества (абсолютного числа) и доли (в процентах) пациентов относительно каждой категории. Качественные признаки сравнивались между собой с помощью критерия Пирсона хи-квадрат $\left(\chi^{2}\right)$ с поправкой Йетса и точного критерия Фишера (F). Все количественные признаки тестировались на нормальность распределения с помощью критерия Шапиро-Уилка. Для сравнительного анализа количественных признаков использовали критерий Стьюдента (t). Для анализа зависимостей между выборками были найдены коэффициенты корреляции Пирсона.

\section{РЕЗУЛЬТАТЫ И ОБСУЖДЕНИЕ}

При проведении исследования обращал на себя внимание факт высокой распространенности патогенных факторов в пре- и перинатальном периодах, обусловливающих резидуально-органическую церебральную недостаточность в основной группе $(100 \%, \mathrm{n}=192)$ и снижающих защитноприспособительные механизмы деятельности головного мозга в контрольной группе $(48 \%, \mathrm{n}=100)$.

Экстрагенитальная патология среди матерей детей основной группы обнаружена статистически значимо чаще $(\mathrm{p} \leq 0,01)$, чем в контрольной группе (90,6\% против $46 \%)$.

Патологическое течение беременности преобладало среди матерей в основной группе $(92,7 \%$, $\mathrm{n}=178)$. В данную группу входили дети, рожденные от матерей с отягощённым акушерскогинекологическим анамнезом или патологическим течением беременности (токсикозы первой и второй половины), в связи с чем более трети женщин (40,6\%, n=78) получали лечение по поводу угрозы прерывания беременности в акушерско-гинекологическом стационаре. В контрольной группе детей патологическое течение беременности у матерей зафиксировано статистически значимо $(\mathrm{p} \leq 0,01)$ реже $(40 \%, \mathrm{n}=100)$.

Патология, установленная в родах, также имела статистически значимые отличия $(\mathrm{p} \leq 0,01)$ : $85,4 \%$ случаев в основной группе против $36,0 \%$ в контрольной группе. Наиболее частыми осложнениями родов на уровне статистической значимости $(\mathrm{p} \leq 0,01)$ являлись асфиксия плода и перинатальная травма: основная группа - 71,9\% и $82,3 \%$ случаев, контрольная группа - 6,0\% и $18,0 \%$ случаев соответственно.

Результаты характеристик пре- и перинатальных факторов у обследованных детей основной и контрольной групп представлены на рисунке 1 .

Влияние патогенных факторов обусловливало особенности психофизического развития детей. Очевидно, что психопатологическая симптоматика на ранних этапах онтогенеза определяла клиническую картину возрастных проявлений резидуально-органических расстройств $[1,2,4,6,8$, 9]. Начиная с 4-летнего возраста (психомоторный этап нервно-психического реагирования) на фоне постепенного снижения невропатической симптоматики нарастали астеногипердинамические проявления разной степени выраженности, обусловливающие гиперкинетическое поведение с нарушением функции внимания.

Учащение и усиление клинических проявлений энкопреза происходило на фоне инфекций, частых простуд, эмоционально насыщенных ситуаций, переутомления, нарушения привычного режима сна-бодрствования, имело сезонную обусловленность (осенне-весенний период). 


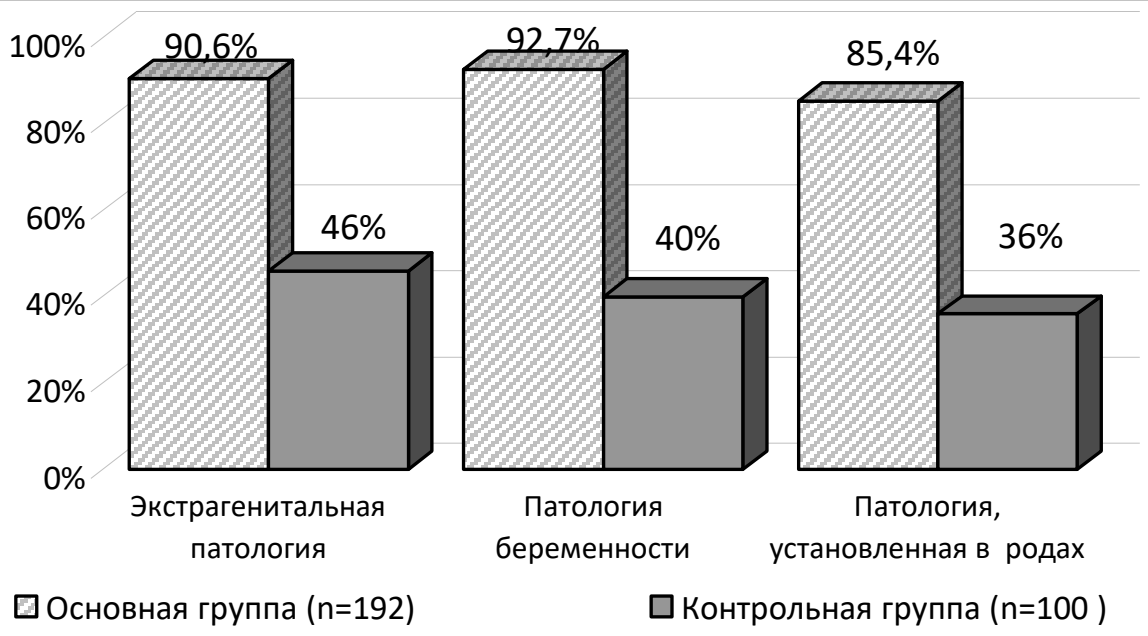

Р и с у н о к 1. Распределение пре- и перинатальных факторов, связанных с патологией беременности и родов у матерей обследованных детей основной и контрольной групп $(p \leq 0,01)$

В понимании механизмов патогенеза энкопреза важная роль принадлежит электрофизиологическому исследованию. Полученные данные ЭЭГ у детей с неорганическим энкопрезом в подавляющем большинстве случаев $(91,5 \%)$ свидетельствовали о нарушениях биоэлектрической активности головного мозга. Согласно классификации Л.Р. Зенкова (1995), указанные особенности ЭЭГ могут быть отнесены к пограничному и патологическому типам $[10,11,12]$.

Патологический тип ЭЭГ в основной группе выявлен более чем в трети случаев $(35,4 \%, \mathrm{n}=68)$ и характеризовался диффузными патологическими колебаниями в фоновой записи, очаговой высокоамплитудной полиморфной активностью. Диффузные патологические колебания определяли разнообразный характер ритмов ЭЭГ $(\alpha-, \theta-$ и $\delta$-диапазонов), в основном высокой амплитуды, превышающие 130-150 мкв. Комплексы «спайк медленная волна», «острая волна - медленная волна» и другие эпилептиформные колебания носили облигатный характер. Функциональная нагрузка приводила к генерализации патологической активности со значительным увеличением её амплитуды, к возникновению эпилептиформной активности, длительному периоду последействия. В контрольной группе патологический тип ЭЭГ был обнаружен статистически значимо $(\mathrm{p} \leq 0,01)$ реже $(12 \%, \mathrm{n}=12)$, чем в основной группе.

Пограничный тип ЭЭГ в основной группе отмечался более чем в половине наблюдений $(58,3 \%, \mathrm{n}=112)$ и характеризовался сдвигом нормальной частоты доминирующего ритма с появлением патологических колебаний в фоновой записи. При этом функциональные пробы вызывали асимметрию формирующегося $\alpha$-ритма, практически его редукцию, полиритмию со вспышками редких патологических колебаний, генерализацию $\theta$ - и $\delta$-волн, нестойкую (проходящую в течение 20 секунд) гиперсинхронизацию медленных волн. В контрольной группе пограничный тип ЭЭГ встречался статистически значимо $(\mathrm{p} \leq 0,01)$ с более редкой частотой $(32 \%, \mathrm{n}=32)$.

Нормальный тип ЭЭГ в основной группе детей был зарегистрирован с более редкой статистически значимой частотой $(\mathrm{p} \leq 0,01)-6,3 \%$ случаев против 56,0\% случаев в контрольной группе.

Структура ЭЭГ-картины у обследованных детей основной и контрольной групп приводится на рисунке 2.

Объяснением различной типологии вариантов ритмов ЭЭГ при энкопрезе служит различная степень выраженности и локализация органического поражения коры головного мозга.

Обработка результатов нейропсихологического обследования включала ряд последовательных этапов и позволила провести их качественный и количественный анализ. Данные о характере допускаемых при выполнении заданий ошибок, о динамических и временных параметрах деятельности, об особенностях реакции ребенка на ошибки, о возможности их самостоятельной коррекции были оценены по 4-балльной системе оценок, предложенной А.Р. Лурия [13, 14, 15].

«0»- выставляется в тех случаях, когда ребенок без дополнительных разъяснений выполняет предложенную экспериментальную программу; «1»- если отмечается ряд мелких погрешностей, исправляемых самим ребенком без участия экспериментатора; по сути «1» - это нижняя нормативная граница; «2»- ребенок в состоянии выполнить задание после нескольких попыток, подсказок и наводящих вопросов экспериментатора; «3» - задание недоступно для выполнения даже после развернутой помощи ребенку со стороны экспериментатора. 


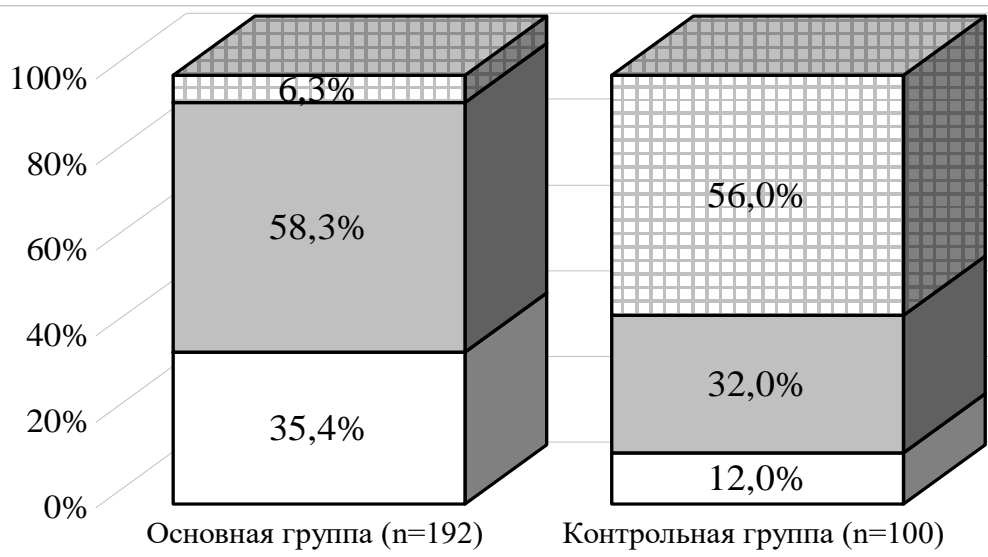

口Патологическая ЭЭГ $\quad \square$ Пограничная ЭЭГ $\quad \square$ Нормальная ЭЭГ

\section{Р и с у н о к 2. Распределение типов ЭЭГ у обследованных детей основной и контрольной групп}

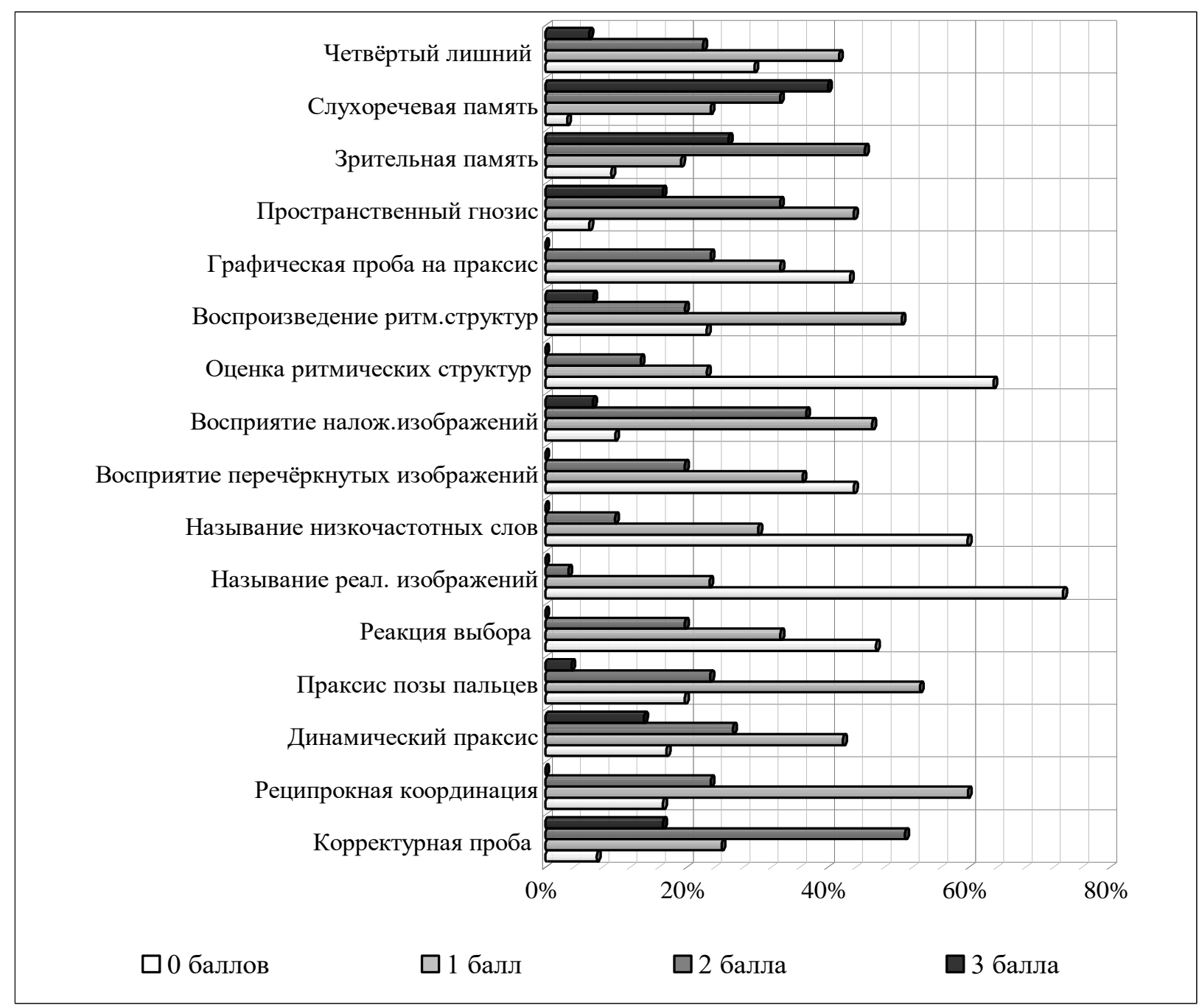

\section{Р и с у н о к 3. Результаты нейропсихологического обследования детей основной группы}

Распределение результатов нейропсихологического обследования детей основной группы $(\mathrm{n}=192)$ представленона рисунке 3.
Распределение результатов нейропсихологического обследования детей контрольной группы $(\mathrm{n}=100)$ показано на рисунке 4. 


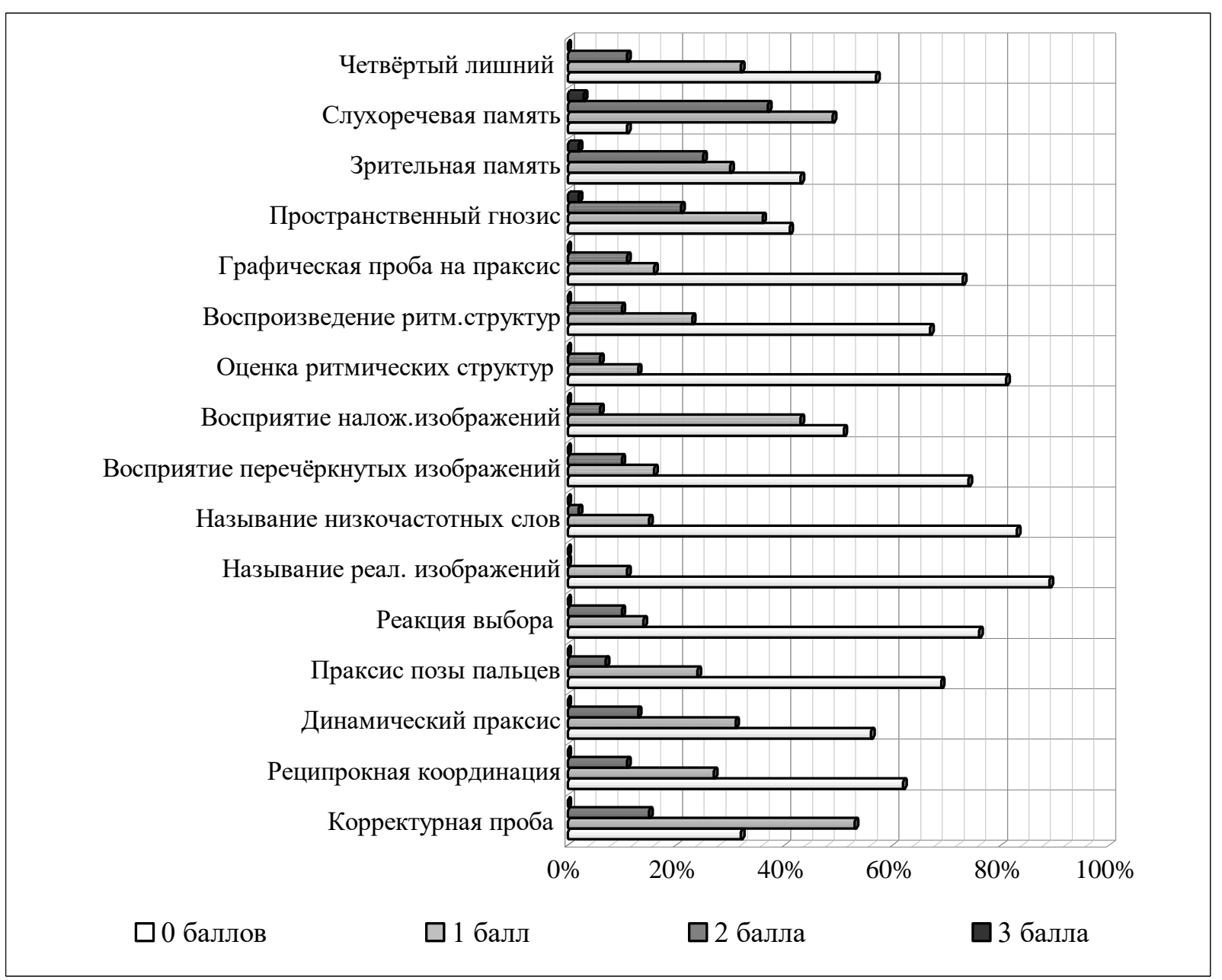

Р и с у н о к 4. Результаты нейропсихологического обследования детей контрольной группы

В ходе проведенного исследования с использованием качественной оценки уровня выполнения заданий наиболее грубые ошибки (неспособность выполнить задание) при заучивании слов на слух с оценкой 3 балла статистически значимо $(\mathrm{p} \leq 0,05)$ чаще допускали дети основной группы (40,1\%, $\mathrm{n}=77)$, чем дети контрольной группы $(3 \%, \mathrm{n}=3)$.

При выполнении корректурной пробы и методики определения объема зрительной памяти (заучивание предметов) в помощи экспериментатора нуждались 51,0\% и 45,3\% обследованных детей основной группы, их оценка составляла 2 балла. Тогда как в контрольной группе число детей, которым требовалось содействие экспериментатора, было статистически значимо $(\mathrm{p} \leq 0,01)$ меньше $-15,0 \%$ и $25,0 \%$ соответственно.

Ряд погрешностей с самостоятельной коррекцией совершенных ошибок отмечался у детей основной группы при выполнении следующих проб: реципрокная координация $(59,89 \%, \mathrm{n}=115)$, динамический праксис $(42,2 \%, \mathrm{n}=81)$, праксис позы пальцев $(53,1 \%, \mathrm{n}=102)$, восприятие наложенных изображений $(46,35 \%, \mathrm{n}=89)$, воспроизведение ритмических структур $(50,5 \%, \mathrm{n}=97)$, простран- ственный гнозис $(43,75 \%, \mathrm{n}=84)$, исключение предметов (четвёртый лишний) $(41,66 \%, \mathrm{n}=80)$. Результаты выполнения заданий по этим субтестам были оценены в 1 балл.

В то время как у детей из контрольной группы статистически значимо $(\mathrm{p} \leq 0,05)$ с более редкой частотой зарегистрированы показатели, оценённые в 1 балл, по следующим пробам: реципрокная координация $(27 \%, \mathrm{n}=27)$, динамический праксис (31\%, n=31), праксис позы пальцев $(24 \%, n=24)$, восприятие наложенных изображений (43\%, $\mathrm{n}=43)$, воспроизведение ритмических структур $(23 \%, n=23)$, пространственный гнозис $(36 \%$, $\mathrm{n}=36$ ), исключение предметов (четвёртый лишний) $(32 \%, \mathrm{n}=32)$.

В целом проведенное нами нейропсихологическое исследование позволило выявить в большинстве случаев «выпадение» первого (энергетического) блока в соответствии со структурнофункциональной моделью организации работы мозга по А.Р. Лурия, эффективная деятельность которого определяется мозговыми структурами. К числу этих структур относятся ретикулярная формация, неспецифические структуры среднего 
мозга (диэнцефальные отделы), лимбическая система и медиобазальные отделы лобных и височных долей мозга. Энергетический блок отвечает за регуляцию процессов активации мозга, имеет прямое отношение к процессам внимания и памяти, а также считается непосредственным мозговым субстратом различных мотивационных, эмоционально-поведенческих, волевых процессов и состояний. Вероятно, причиной установленных нарушений нейропсихологических функций при энкопрезе является резидуально-органическая церебральная недостаточность врожденного генеза, обусловленная влиянием патогенных факторов на ранних этапах онтогенеза.

\section{ВЫВОДЫ}

На основе анализа особенностей пре- и перинатального периодов онтогенеза детей с энкопрезом, отчетливых пароксизмальных эпилептиформных ЭЭГ-отклонений и с учетом их соотнесения с клиническими проявлениями редуцированного психоорганического синдрома, подтверждаемыми недостаточностью функционирования головного мозга по итогам нейропсихологического исследования, можно предположить, что в основе манифестации и клинической динамике энкопреза лежат схожие с эпилептогенезом центральные механизмы патогенеза. Энкопрез у детей является следствием сформированной патологической системы, обусловленной резидуальноорганической церебральной недостаточностью, вследствие влияния патогенных факторов на раннем этапе онтогенеза. Нарушение интрацентральной корково-подкорковой регуляции головного мозга сопровождается утратой контроля над актом дефекации. Данная патология занимает промежуточное положение между невротическими расстройствами и известными формами эпилепсии, это соответствует точке зрения А.И. Болдырева, что энкопрез относится к спектру нарушений, пограничным образом относящихся к эпилепсии [16].

\section{КОНФЛИКТ ИНТЕРЕСОВ}

Автор заявляет об отсутствии явных и потенциальных конфликтов интересов в связи с публикацией данной статьи.

\section{ИСТОЧНИК ФИНАНСИРОВАНИЯ}

Автор заявляет об отсутствии финансирования или спонсорской помощи при проведении исследования.

\section{СООТВЕТСТВИЕ ПРИНЦИПАМ ЭТИКИ}

Исследование проведено с соблюдением норм современной биомедицинской этики и этических стандартов, разработанных в соответствии с Хельсинской декларацией ВМА (протокол заседания этического комитета НИИ психического здоровья Томского НИМЦ № 53/1.2012 от 1 октября 2012 г.).

\section{ЛИТЕРАТУРА/REFERENCES}

1. Фесенко Ю.А. Возрастная физиология и психофизиология: энурез и энкопрез у детей. Практическое пособие. 2-е изд. М. : Изд-во Юрайт, 2018: 168. Fesenko YuA. Age physiology and psychophysiology: enuresis and encopresis in children. A practical guide. Second edition. Moscow: Yurayt Publishing House, 2018: 168 (in Russian).

2. Буторина Н.Е., Ретюнский К.Ю. Затяжные системные расстройства в детском возрасте (клиника, патогенез, терапия). Екатеринбург : Издво «Экспресс-Дизайн», 2005: 280. Butorina NE., Retyunsky KYu. Prolonged systemic disorders in childhood (clinical picture, pathogenesis, therapy). Yekaterinburg: Express-Design Publishing House, 2005: 280 (in Russian).

3. Шанько Г.Г., Михайлов А.Н. Энкопрез не органической природы. Учебно-методическое пособие. Минск: БелМАПО, 2007: 26. Shanko GG., Mikhailov AN. Encopresis is not organic in nature. Study guide. Minsk: Publishing House Belarusian Medical Academy of Postgraduate Education, 2007: 26 (in Russian).

4. Куташов В.А., Сахаров И.Е. Неврология и психиатрия детского возраста. Воронеж: Изд-во Воронежская ГМА им. Н.Н. Бурденко, 2015: 502-511. Kutashov VA, Sakharov IE. Pediatric neurology and psychiatry. Voronezh: Voronezh State Medical Academy named after N.N. Burdenko, 2015: 502-511 (in Russian).

5. Гречаный С.В., Ильичев А.Б., Поздняк В.В., Кощавцев А.Г. Общая психопатология. Учебное пособие. СПб.: СПбГПМУ, 2020: 76. Grechanyy SV, Ilyichev AB, Pozdnyak VV, Koschavtsev AG. General Psychopathology. Schoolbook. Saint Petersburg: Publishing house Saint Petersburg State Pediatric Medical University, 2020: 76 (in Russian).

6. Капралова В.И. Патология, приводящая к ограничению жизнедеятельности, у детей с недержанием мочи и кала. Формы и методы социальной работы в различных сферах жизнедеятельности: Материалы VIII Междунар. научнопракт. конф. Улан-Удэ, 2019: 103-104. Kapralova VI. Pathology leading to limitation of vital functions in children with urinary and fecal incontinence. Forms and methods of social work in various spheres of life: Materials of the VIII International Scientific and Practical Conference. UlanUde, 2019: 103-104 (in Russian).

7. Немых Л.С., Куташов В.А., Ульянова О.В., Хабарова Т.Ю. Эмоциональные и поведенческие расстройства детского возраста: системные неврозы, заикание, энурез, энкопрез. Воронеж: Изд-во Ритм, 2017: 208. Nemykh LS, Kutashov VA, Ulyanova OV., Khabarova TYu. Emotional and behavioral disorders of childhood: systemic neuroses, stuttering, enuresis, encopresis. Voronezh: Publishing House Ritm, 2017: 208 (in Russian). 
8. Моисеев А.Б., Миронов А.А., Кольбе О.Б. Нарушения мочеиспускания и сочетанные нарушения функции тазовых органов у детей: подходы к диагностике, лечению и профилактике. Вестник Российского государственного медицинского университета. 2018: 5: 62-69. Моіseev AB, Mironov AA, Kolbe OB. Violations of urination and associated disorders of the pelvic organs in children: approaches to diagnosis, treatment and prevention. Bulletin of the Russian State Medical University. 2018: 5: 62-69 (in Russian). DOI: $10.24075 /$ vrgmu.2018.067

9. Калантаров Т.К. Возможность лечения каловой инконтиненции у детей. Медицинский Совет. 2019;(11):157-159. Kalantarov TK. Possibility of treatment of fecal incontinence in children. Medical Council. 2019;(11):157-159 (in Russian). https://doi.org/10.21518/2079-701X-2019-11-157-159

10. Болдырев А.И. Пограничные формы эпилепсии. XII съезд психиатров России (материалы съезда). М., 1995: 321-323. Boldyrev AI. Borderline forms of epilepsy. XII Congress of Russian Psychiatrists (materials of the Congress). Moscow, 1995: 321-323 (in Russian).

11. Благосклонова Н.К. Электроэнцефалограмма у детей и подростков в норме и при некоторых пограничных психических расстройствах. Лекция. М.: ЦОЛИУВ, 1988: 28. Blagosklonova NK. Electroencephalogram in children and adolescents in normal conditions and with some borderline mental disorders. Lecture. Moscow: Publishing House Central Institute for Advanced Training of Doctors, 1988: 28 (in Russian).

12. Зенков Л.Р. Клиническая энцефалография (с элементами эпилептологии). Руководство для врачей. 7-е издание. М.: МЕДпресс-информ, 2018: 360. Zenkov L.R. Clinical Encephalography (with elements of epileptology). Handbook for Doctors. Seventh edition. Moscow: Publishing House MEDpress-inform, 2018: 360 (in Russian).

13. Лурия А.Р. Основы нейропсихологии (учебное пособие для студентов высших учебных заведе- ний). М., Издательский центр «Академия», 2003: 220-232. Luria AR. Fundamentals of Neuropsychology (textbook for students of higher educational institutions). Moscow: Publishing Center "Academy", 2003: 220-232 (in Russian).

14. Березкин Д.В. Диагностика и нейропсихологическая коррекция детей с неврозоподобными энурезом и энкопрезом. Клиническая и специальная психология. 2017; 6(1): 48-62. Berezkin DV. Diagnostics and neuropsychological correction of children with neurosis-like enuresis and encopresis. Clinical and Special Psychology. 2017; 6(1): 48-62 (in Russian). DOI: $10.17759 /$ cpse.2017060104

15. Цветкова Л.С. Методика нейропсихологической диагностики детей (Методический альбом). М., Педагогическое общество России, 2002: 96. Tsvetkova LS. Methods of neuropsychological diagnostics of children (Methodical album). Moscow: Publishing House Pedagogical Society of Russia, 2002: 96 (in Russian).

16. Gonring K, Dolan B, Kapke TL, Begotka A, Sood M, Silverman AH. Group Treatment of Fecal Incontinence: A Description of an Interdisciplinary Intervention. J Pediatr Gastroenterol Nutr. 2019 Sep;69(3):e70-e74. doi: 10.1097/MPG.0000000000002372

17. Santos JD, Lopes RI, Koyle MA. Bladder and bowel dysfunction in children: An update on the diagnosis and treatment of a common, but underdiagnosed pediatric problem. Can Urol Assoc J. 2017 Jan-Feb;11(1-2Suppl1):S64-S72. doi: 10.5489/cuaj.4411

18. Anderson B. Physical Therapy for a Child with Encopresis: A Case Report. Pediatr Phys Ther. 2019 doi: 10.1097/PEP.0000000000000631

Поступила в редакцию 04.09.2020

Утверждена к печати 30.11.2020

Бебенин Александр Алексеевич, врач-психиатр, заведующий психиатрическим отделением № 3, Свердловская областная клиническая психиатрическая больница.

Бебенин Александр Алексеевич, bebenin_aа@mail.ru 
UDC 616-008.222:612.365-053.2:616-08.63:611.81

For citation: Bebenin A.A. The role of organic brain dysfunction in the formation of inorganic encopresis in childhood. Siberian Herald of Psychiatry and Addiction Psychiatry. 2020; 4 (109): 34-41. https://doi.org/10.26617/18103111-2020-4(109)-34-41

\title{
The role of organic brain dysfunction in the formation of inorganic encopresis in childhood
}

\section{Bebenin A.A.}

${ }^{1}$ GBUZ Sverdlovsk Region "Sverdlovsk Regional Clinical Psychiatric Hospital" Siberian Tract, 8 km, 620030, Yekaterinburg, Russian Federation

\begin{abstract}
The article presents the results of a long-term study of inorganic encopresis in childhood and adolescence. Objective: to study the factorial causation of inorganic encopresis based on the systematization and analysis of data from a complex clinical and paraclinical study (anamnestic, neurological, electrophysiological, neuropsychological studies). Material and Methods. The study examined 192 cases of inorganic encopresis with a prolonged unfavorable course. The research sample included children with non-organic encopresis (F98.1 according to ICD-10), aged 5 to 13 years, with a general intellectual indicator according to the Wechsler scale not lower than the average (90-109 points). All children were examined by a pediatrician and gastroenterologist to exclude pathology of the gastrointestinal tract. The comparison was carried out with similar indicators of the same age groups of children and adolescents $(n=100)-$ the control group. The clinical method was used as the main method in order to establish the clinical-psychopathological, clinical-dynamic patterns of the development of inorganic encopresis. According to the results of a computer EEG, violations of the bioelectrical activity of the brain were verified. Results. A comprehensive clinical and paraclinical study has demonstrated that the formation of encopresis is due to residual organic cerebral insufficiency due to the influence of pathogenic factors at the early stage of ontogenesis (prenatal and perinatal periods), which was detected in $100 \%$ of cases. The reliability of organic brain dysfunction during encopresis was verified by the data of neurological, electrophysiological, and neuropsychological studies. Correlation of distinct epileptiform EEG patterns with clinical manifestations of psychoorganic disorders indicates that mechanisms similar to epileptogenesis are involved in the development of encopresis with a prolonged unfavorable course.
\end{abstract}

Keywords: encopresis of inorganic nature, pathogenesis, electroencephalogram, neuropsychology, children of preschool and school age.

Received September 04.2020

Accepted November 30.2020

Bebenin Alexander A., psychiatrist, head of the psychiatric department no. 3, Sverdlovsk Regional Clinical Psychiatric Hospital, Yekaterinburg, Russian Federation.

Bebenin Alexander A., bebenin_aa@mail.ru 